\title{
Short communication: The effect of heat treatment of bovine colostrum on the concentration of oligosaccharides in colostrum and in the intestine of neonatal male Holstein calves
}

Amanda J. Fischer, Nilusha Malmuthuge, Le Luo Guan, and Michael A. Steele ${ }^{1}$

Department of Agricultural, Food and Nutritional Science, University of Alberta, Edmonton, Alberta, Canada T6G 2P5

\begin{abstract}
The objective of this study was to determine the effect of the heat treatment $\left(\mathrm{HT}, 60^{\circ} \mathrm{C}\right.$ for $\left.60 \mathrm{~min}\right)$ on the concentration of bovine colostrum oligosaccharides (bCO) in pooled bovine colostrum and the intestine of neonatal male Holstein calves after feeding. Firstmilking colostrum was pooled from both primiparous and multiparous cows, and half of the pooled colostrum was heat-treated at $60^{\circ} \mathrm{C}$ for $60 \mathrm{~min}(\mathrm{HC})$, whereas the other half was not heat-treated and remained fresh (FC). At birth, 32 male Holstein calves were randomly assigned to 1 of 3 treatment groups: (1) control calves that did not receive colostrum for the duration of the experiment and were euthanized at $6 \mathrm{~h}(\mathrm{NC}, \mathrm{n}=4)$ or $12 \mathrm{~h}(\mathrm{NC}, \mathrm{n}=4),(2)$ calves fed fresh colostrum (FC) and were euthanized at $6 \mathrm{~h}(\mathrm{FC}, \mathrm{n}=6)$ or $12 \mathrm{~h}(\mathrm{FC}, \mathrm{n}$ $=6)$, or (3) calves fed heat-treated colostrum (HC) and euthanized at $6 \mathrm{~h}(\mathrm{HC}, \mathrm{n}=6)$ or $12 \mathrm{~h}(\mathrm{HC}, \mathrm{n}=6)$. All calves were fed $2 \mathrm{~L}$ of colostrum within $1 \mathrm{~h}$ after birth. At dissection, digesta of the distal jejunum, ileum, and colon was collected and analyzed by liquid chromatography-mass spectrometry to determine the concentration of bCO within each intestinal region. The heat-treated colostrum displayed numerically higher concentrations of total bCO $(3,511.6 \mu \mathrm{g} / \mathrm{g})$ when compared with fresh colostrum $(1,329.9 \mu \mathrm{g} / \mathrm{g})$, with $3^{\prime}$-sialyllactose being the most abundant bCO in both fresh and HT colostrum. In contrast, calves fed HT colostrum displayed a lower amount of total bCO in the distal jejunum $(221.91 \pm$ 105.3 vs. $611.26 \pm 265.1 \mu \mathrm{g} / \mathrm{g})$, ileum $(64.97 \pm 48.39$ vs. $344.04 \pm 216.87 \mu \mathrm{g} / \mathrm{g})$, and colon $(25.60 \pm 13.1$ vs. $267.04 \pm 125.81 \mu \mathrm{g} / \mathrm{g})$ at $6 \mathrm{~h}$ of life when compared with calves fed fresh colostrum. No differences were observed in regard to the concentrations of total bCO in the intestine of $\mathrm{FC}$ and $\mathrm{HC}$ calves at $12 \mathrm{~h}$ of life. It is speculated that lower concentrations of $\mathrm{bCO}$ in the
\end{abstract}

Received July 20, 2017.

Accepted September 3, 2017.

${ }^{1}$ Corresponding author: masteele@ualberta.ca gastrointestinal tract of $\mathrm{HC}$ calves at $6 \mathrm{~h}$ of life could be due to the early establishment of beneficial bacteria, such as Bifidobacterium, in $\mathrm{HC}$ calves and their subsequent metabolism of bCO as a carbon source. These findings suggest that the heat treatment of colostrum increases the amount of free bCO, which may serve as prebiotics available to microbiota within the intestine of the neonatal calf.

Key words: heat treatment, colostrum, neonatal calf, oligosaccharide

\section{Short Communication}

The neonatal dairy calf is at high risk of morbidity and mortality (NAHMS, 2011), which causes concern not only from an economic standpoint, but also with regard to welfare. The timely feeding of high-quality, adequate volumes of uncontaminated colostrum is a key factor in determining the survival of the neonatal dairy calf (Weaver et al., 2000). However, although the consequences of poor colostrum management are well known, many farms do not assess the quality of colostrum, which may lead to feeding colostrum with a low concentration of IgG or contaminated colostrum, and do not feed the first colostrum meal in a timely manner (Vasseur et al., 2010). Unfortunately, this type of colostrum management likely plays a pivotal role in decreased calf health and welfare, which contributes to high rates of morbidity reported in neonatal calves. More specifically, neonatal calves have an alarmingly high prevalence of enteric infections, with neonatal calf diarrhea being the most common ailment resulting in illness and death (Meganck et al., 2014) and 25.3\% of pre-weaned calves being affected by digestive problems (NAHMS, 2011). Therefore, knowledge regarding how to decrease the prevalence of digestive disorders in preweaning calves is necessary to ensure a profitable dairy industry.

In an effort to improve neonatal calf gut health, interest has been increasing in supplementing bovine colostrum or colostrum replacers with gut active carbo- 
hydrates derived from yeast (mannan-oligosaccharides, MOS) and bacteria (Bifidobacterium galacto-oligosaccharides; Brady et al., 2015). However, the majority of studies using large sample sizes have found a negative or no effect on calf performance and passive transfer of immunity when MOS or Bifidobacterium galacto-oligosaccharides are supplemented (Villettaz Robichaud et al., 2014; Brady et al., 2015). During early life, the gastrointestinal tract (GIT) of the calf is evolutionarily tailored to respond to compounds secreted by the dam into colostrum and milk, and the structure of an oligosaccharide is a major determinant of biological function (Short et al., 2016). For instance, MOS are particularly effective at adhering to Escherichia coli when present in an $\alpha 1-3$ and $\alpha 1-6$ configuration (Firon et al., 1987), while sialylated oligosaccharides (OS) are most effective as $\alpha 2-6$ isomers (Martin et al., 2002). Therefore, these differences in structure and configuration may provide reasoning as to why the supplementation of MOS may not have a beneficial effect on the calf GIT during early life, as it may better respond to bovine colostrum oligosaccharides (bCO) structures during this period. Martin-Sosa et al. (2003) determined 5 primary OS compounds present in bovine colostrum and milk, with significantly higher amounts of specific OS present in colostrum compared with mature milk. More than $70 \%$ of the identified OS in bovine colostrum and milk are sialylated (Tao et al., 2008), with 3 '-sialyllactose being the most abundant isoform in colostrum, followed by 6 '-sialyllactosamine (Martin-Sosa et al., 2003). Using in vitro experiments, it has been demonstrated that oligosaccharides are able to resist enzymatic hydrolysis throughout the upper GIT and it was previously thought that the majority of OS reach the colon intact for fermentation by commensal microbiota (Engfer et al., 2000). However, a recent study using a rat model showed that the intestinal bacteria might metabolize human milk-derived OS as early as the jejunum and that smaller molecular weight OS may actually never reach the colon (Jantscher-Krenn et al., 2013).

Currently, knowledge is lacking regarding methods to increase the availability of oligosaccharides in bovine colostrum for supplementation in dairy calves, as well as the characterization of bCO concentrations in the neonatal calf intestine. Therefore, the objectives of the present study were to (1) determine the effect of the heat treatment of colostrum on the concentration of bCO, and (2) to determine the concentrations of $\mathrm{bCO}$ in the distal jejunum, ileum, and colon of neonatal calves fed heat-treated (HT) colostrum compared with calves fed fresh colostrum. It was hypothesized that HT colostrum would have higher concentrations of free bCO when compared with fresh colostrum, and as a consequence, calves fed HT colostrum would have higher concentrations of bCO within the intestine compared with calves fed fresh colostrum.

The experimental procedures were conducted at the Dairy Research and Technology Centre, University of Alberta in accordance with the Canadian Council of Animal Care (CCAC, 1993), and all protocols were approved by the University of Alberta Animal Care and Use Committee for Livestock (AUP00001012). Colostrum (first milking) containing $\geq 50 \mathrm{mg} / \mathrm{mL}$ of $\operatorname{IgG}$ was collected from 16 primiparous and multiparous cows and immediately frozen at $-20^{\circ} \mathrm{C}$ after collection. Once the required volume was collected, colostrum was thawed and pooled. Half of the pooled colostrum (24 L) was heat-treated for $60 \mathrm{~min}$ at $60^{\circ} \mathrm{C}$ using a pasteurizer (DT 10G, Dairy Tech Inc., Greeley, CO). Both fresh and $\mathrm{HT}$ colostrum were frozen at $-20^{\circ} \mathrm{C}$ until needed. At birth, male Holstein calves were randomly assigned to 1 of 3 treatment groups: (1) control calves that did not receive colostrum for the duration of the experiment and euthanized at $6 \mathrm{~h}(\mathrm{NC}, \mathrm{n}=4)$ or $12 \mathrm{~h}(\mathrm{NC}$, $\mathrm{n}=4),(2)$ calves fed fresh colostrum and euthanized at $6 \mathrm{~h}(\mathbf{F C}, \mathrm{n}=6)$ or $12 \mathrm{~h}(\mathrm{FC}, \mathrm{n}=6)$, or (3) calves fed pasteurized colostrum and euthanized at $6 \mathrm{~h}(\mathbf{H C}$, $\mathrm{n}=6)$ or $12 \mathrm{~h}(\mathrm{HC}, \mathrm{n}=6)$. Prior to the study, because no previous research has been conducted with regard to the concentrations of oligosaccharides in the intestine of neonatal calves, studies regarding the proportion of Bifidobacterium in the small intestine of neonatal calves were used as a variable to determine the amount of biological replicates required to have sufficient power for the experiment. It was determined that a minimum of 4 biological replicates was required to detect a $20 \%$ difference at a power of $80 \%$. The average birth BW of FC calves euthanized at 6 and $12 \mathrm{~h}$ were $40.9 \pm$ 3.4 and $39.1 \pm 1.5 \mathrm{~kg}$, respectively, and for $\mathrm{HC}$ calves euthanized at 6 and $12 \mathrm{~h}$ were $47.7 \pm 3.3$ and 41.4 $\pm 2.1 \mathrm{~kg}$, respectively. Using a water bath, colostrum was thawed to $38^{\circ} \mathrm{C}$ and $2 \mathrm{~L}$ was fed to each calf using an esophageal tube feeder within an hour after birth. Immediately before euthanasia, $\mathrm{FC}$ and $\mathrm{HC}$ calves euthanized at $6 \mathrm{~h}$ achieved serum $\operatorname{IgG}$ concentrations of $9.7 \pm 0.74$ and $9.7 \pm 0.70 \mathrm{mg} / \mathrm{mL}$, respectively, whereas $\mathrm{FC}$ and $\mathrm{HC}$ calves euthanized at $12 \mathrm{~h}$ achieved 15.8 \pm 1.37 and $12.9 \pm 1.37 \mathrm{mg} / \mathrm{mL}$, respectively (KentDennis, 2014). Calves were euthanized by penetrative captive bolt followed by exsanguination. The digesta samples were collected following the procedures previously reported by Malmuthuge et al. (2015). Briefly, closed intestinal segments $(10 \mathrm{~cm})$ of the distal jejunum, ileum, and colon were collected with the distal jejunum defined as $30 \mathrm{~cm}$ proximal to the collateral branch of the mesenteric artery, the ileum defined as $30 \mathrm{~cm}$ proximal to the ileo-cecal junction, and the colon defined as $30 \mathrm{~cm}$ distal to the colon-cecal junction. 
After collection, digesta samples were snap-frozen in liquid nitrogen and transferred to $-80^{\circ} \mathrm{C}$ until further analysis.

After thawing digesta samples for 5 min on ice, approximately $0.10 \mathrm{~g}$ of each sample was obtained and placed in a $2-\mathrm{mL}$ microcentrifuge tube. This was followed by the addition of $150 \mu \mathrm{L}$ of HPLC-grade water and defatting by centrifugation at $6,000 \times g$ for $15 \mathrm{~min}$ at room temperature, and the supernatant was removed and placed in a new tube. After repeating the above step twice, $1 \mathrm{~mL}$ of 2:1 chloroform:methanol was added to the supernatant and centrifugation was performed at $300 \times g$ for $60 \mathrm{~min}$ at room temperature to remove any proteins and impurities. The lower phase was then re-extracted using $500 \mu \mathrm{L}$ of $50 \%$ methanol, and the resulting supernatant was cooled at $4^{\circ} \mathrm{C}$ for $30 \mathrm{~min}$. The sample was then centrifuged at $11,000 \times g$ for 15 min at room temperature to remove any residual contaminants and diluted 5-fold using 95\% acetonitrile (AcN). Colostrum was processed using the same procedures, except that it was only defatted by centrifugation once and diluted 5-fold before chloroform:methanol extraction. All samples were stored at $4^{\circ} \mathrm{C}$ until liquid chromatography (LC)-MS analysis. The recovery rate of the OS extraction method was assessed by spiking a known amount of internal standard ( $\beta 1-3$-gal- $N$-acetyl-galactosaminyl31-4-gal $\beta 1-4-G l c ;$ GalNAc) before OS extraction and was measured by LC-MS and estimated to be $97 \%$.

Oligosaccharide standards, including disialyllactose (DSL), 3'-sialyllactose (3'-SL), 6'-sialyllactose (6'-SL), $3^{\prime}$-sialyllactosamine $\left(\mathbf{3}^{\prime}\right.$-SLN), and $6^{\prime}$-sialyllactosamine (6'-SLN), and GalNAc (internal standard), were purchased from Dextra Laboratories Ltd. (Reading, UK) and diluted using $95 \% \mathrm{AcN}$ to give a 9-point calibration curve. An LC system with a binary pump and autosampler (Agilent Technologies, Palo Alto, CA) coupled to a 4000 QTRAP mass spectrometer (AB SCIEX, Concord, ON, Canada) was used to determine the concentration of bCO in colostrum and intestinal digesta.
Liquid chromatography separation was performed using an Ascentis Express hydrophilic interaction liquid chromatography column $(10 \mathrm{~cm} \times 2.1 \mathrm{~mm}, 2.7 \mu \mathrm{m}$ in particle size; Sigma, St. Louis, MO), with the mobile phase being composed of (A) water with $50 \mathrm{~m} M$ ammonium acetate, and (B) AcN. The total run time was 35 min (including re-equilibration) with a constant flow rate of $200 \mu \mathrm{L} / \mathrm{min}$. The gradient used was as follows: 0 to $18 \mathrm{~min}, 5$ to $30 \% \mathrm{~A} ; 18$ to $20 \mathrm{~min}, 30 \%$ A; $20.1 \mathrm{~min}$ increased to $50 \% \mathrm{~A} ; 20$ to $24 \mathrm{~min}$ held at $50 \% \mathrm{~A}$, and then decreased back to $5 \% \mathrm{~A}$ at $24.1 \mathrm{~min}$ for column reequilibrium over $11 \mathrm{~min}$ before the next injection. The auto-sampler temperature was set to $15^{\circ} \mathrm{C}$ with $5 \mu \mathrm{L}$ of injection volume. A turbo spray ion source (electrospray ionization) was used under negative ion mode and multiple reaction-monitoring (MRM) scan mode was developed for the quantification of the analytes of interest. Nitrogen was used as curtain gas, nebulizing gas, and drying gas. The instrument was operated using the following settings: curtain gas, gas 1, and gas 2 at 20, 50 , and 50 arbitrary units, respectively, and ionspray voltage at $-4.5 \mathrm{kV}$. The ion source temperature was $400^{\circ} \mathrm{C}$ and quadrupoles Q1 and Q3 were operating at unit mass resolution. The multiple reaction-monitoring transitions and optimized mass spectrometer parameters for each analyte and their reference internal standard (GalNAc) are summarized in Table 1. The data were processed using Analyst 1.6 software (AB SCIEX, Concord, ON, Canada).

To determine the effect of colostrum treatment on the concentration of $\mathrm{bCO}$ within intestinal region, all data were analyzed using the MIXED procedure of the Statistical Analysis system (ver. 9.4, SAS Institute Inc., Cary, NC). Data were analyzed using the animal as a random effect, and the treatment (HC, FC), sample time $(6 \mathrm{~h}, 12 \mathrm{~h}$ ), and sample type (distal jejunum, ileum, colon) and their interactions as fixed effects, and BW was included as a covariate. For the effect of treatment on the concentration of each bCO $\left(3^{\prime}-\mathrm{SL}, 6^{\prime}-\mathrm{SL}\right.$,

Table 1. Multiple reaction-monitoring (MRM) transitions and optimized parameters ${ }^{1}$ for each compound

\begin{tabular}{|c|c|c|c|c|c|}
\hline Compound(s) ${ }^{2}$ & MRM transitions (amu) & $\mathrm{DP}(\mathrm{eV})$ & $\mathrm{EP}(\mathrm{eV})$ & $\mathrm{CE}(\mathrm{eV})$ & $\mathrm{CXP}(\mathrm{eV})$ \\
\hline $3^{\prime}-\mathrm{SLN} / 6^{\prime}$-SLN & $673 \rightarrow 290$ & -105 & -10 & -44 & -13 \\
\hline $3^{\prime}-\mathrm{SLN} / 6^{\prime}-\mathrm{SLN}$ & $673 \rightarrow 572$ & 50 & 4 & -38 & -13 \\
\hline $3^{\prime}-\mathrm{SL} / 6^{\prime}-\mathrm{SL}$ & $632 \rightarrow 290$ & 40 & 4 & 35 & 3 \\
\hline $3^{\prime}-\mathrm{SL} / 6^{\prime}-\mathrm{SL}$ & $632 \rightarrow 572$ & 45 & 4.5 & 40 & 3 \\
\hline DSL & $932 \rightarrow 632$ & 50 & 4 & 40 & 3 \\
\hline DSL & $932 \rightarrow 581$ & 45 & 4.5 & 40 & 3 \\
\hline Glucose & $706 \rightarrow 628$ & 50 & 6 & 25 & 6 \\
\hline Glucose & $706 \rightarrow 201$ & 50 & 6 & 32 & 6 \\
\hline
\end{tabular}


3'-SLN, 6'-SLN, and DSL) and total bCO, data were analyzed among treatment group by sampling time and sample type and the interaction (treatment $\times$ type, treatment $\times$ time, time $\times$ type, and treatment $\times$ type $x$ time). All values reported are least squares means with significance declared at $P \leq 0.05$ and tendencies at $0.05<P<0.10$.

Using LC-MS, 4 main types of bCO were detected in bovine colostrum, regardless of treatment (Figure 1a). Our study revealed that $3^{\prime}$-SL was the dominant bCO in both HT $(2,390.0 \mu \mathrm{g} / \mathrm{g})$ and fresh $(840.0 \mu \mathrm{g} / \mathrm{g})$ colostrum samples (Figure 1b,c), which is consistent with previous reports (Martin-Sosa et al., 2003; Nakamura et al., 2003; Fong et al., 2011). However, the value of $3{ }^{\prime}$-SL in FC in our study differed from previous stud- ies that had reported values of 354 and $1,245 \mu \mathrm{g} / \mathrm{g}$ of $3^{\prime}$-SL in fresh colostrum (Martin-Sosa et al., 2003; Fong et al., 2011). The differences observed between the present study and previous reports may be attributed to differences in the sampling time after parturition, genetics, and sample size of the various experiments. Specifically, Fong et al. (2011) collected second-milking colostrum from a single Friesian cow, and MartinSosa et al. (2003) obtained samples from 6 multiparous Spanish-Brown cows on d 2 of lactation. In contrast to these 2 experiments, the present study collected pooled fresh, first-milking colostrum from both primiparous and multiparous Holstein cattle. Further research using large sample sizes and frequent sampling throughout the various lactation stages of both primiparous and

\section{(a) bCO in heat-treated and fresh colostrum}

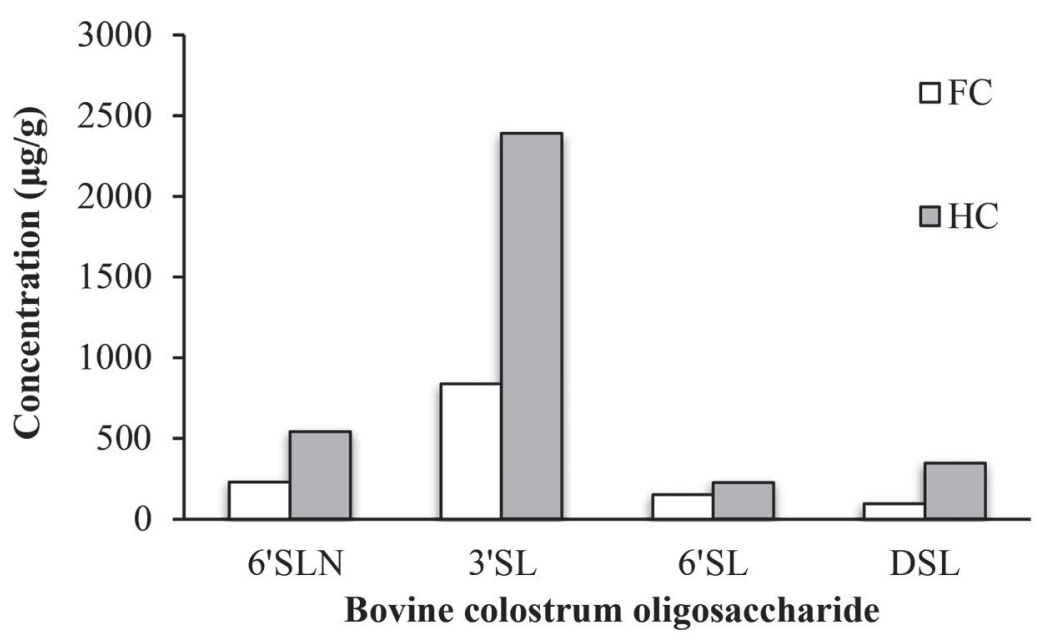

\section{(b) Fresh colostrum}

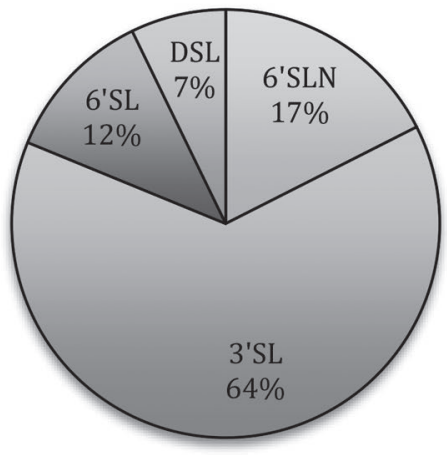

(c) Heat-treated colostrum

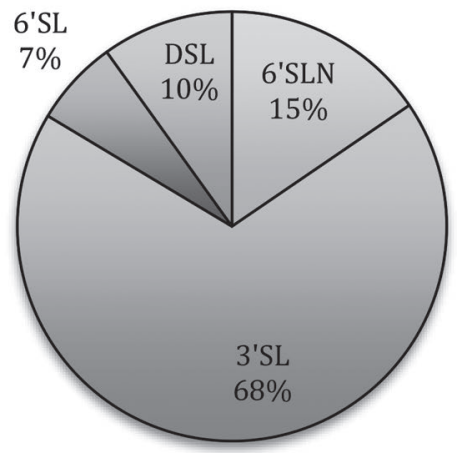

Figure 1. (a) The effect of heat treatment at $60^{\circ} \mathrm{C}$ for $60 \mathrm{~min}$ on the abundance of bovine colostrum oligosaccharides (bCO) between a single pooled bovine fresh colostrum sample and a single heat-treated colostrum sample (numerical differences only). Bars represent the concentration $(\mu \mathrm{g} / \mathrm{g})$ of a single pooled colostrum sample. (b) The proportion of bovine colostrum oligosaccharides in fresh colostrum as a percentage of total oligosaccharides. (c) The proportion of bovine colostrum oligosaccharides in heat-treated colostrum as a percentage of total oligosaccharides. $\mathrm{HC}=$ heat-treated colostrum; $\mathrm{FC}=$ fresh colostrum; $3^{\prime}$-SL $=3^{\prime}$-sialyllactose; $6{ }^{\prime}$-SL $=66^{\prime}$-sialyllactose; $6^{\prime}$-SLN $=6{ }^{\prime}$-sialyllactosamine; DSL $=$ disialyllactose. 
multiparous cows is needed to determine the factors that may greatly influence the concentrations of bCO in colostrum.

Although statistical analysis was not performed for pooled colostrum samples, heat treatment numerically increased $3^{\prime}$-SL by 2.8 times, 6 '-SLN by 2.3 times, $6^{\prime}$-SL by 1.5 times, and DSL by 3.6 times when compared with FC, whereas $3^{\prime}$-SLN was low $(1.1-3.8 \mu \mathrm{g} / \mathrm{g})$ and not different between the 2 types of colostrum samples (Figure 1a). In contrast to human milk, bovine milk contains fewer free oligosaccharides, as they are generally found attached to lipid or protein as glycoconjugate structures (Kobata, 1977; Neeser et al., 1991). The concentration of free oligosaccharides in bovine milk can be increased through heat treatment (Neeser et al., 1991), likely from their cleavage from these structures. Therefore, it is suggested that the cleavage of bCO from colostral lipids or proteins may provide reasoning for the increase in the concentration of free bCO in HT colostrum when compared with fresh colostrum.

In contrast to our hypothesis, although higher concentrations of bCO were detected in HT colostrum, calves fed HT colostrum had a lower concentration of $\mathrm{bCO}$ within intestinal regions at $6 \mathrm{~h}$ when compared with that of calves fed fresh colostrum. As expected, no bCO were detected in the intestine of calves not fed colostrum at either 6 or $12 \mathrm{~h}$ of life. More specifically, at $6 \mathrm{~h}$ of life FC calves tended to have a higher concentration of DSL $(P=0.05)$ and a significantly higher concentration of $6^{\prime}$-SLN $(P=0.02), 6^{\prime}$-SL $(P=$ $0.03)$, and $3^{\prime}$-SL $(P=0.01)$ in the distal jejunum when compared with HC calves (Figure 2). In the ileum, FC calves tended to have a higher concentration of $6^{\prime}$-SLN $(P=0.09)$ and $6{ }^{\prime}$-SL $(P=0.06)$, and a significantly higher concentration of $3^{\prime}$-SL $(P=0.03)$ and DSL $(P$ $=0.04)$ compared with $\mathrm{HC}$ calves. Additionally, the colon of FC calves tended to have a higher concentration of $6^{\prime}$-SLN $(P=0.09), 6^{\prime}$-SL $(P=0.06)$, and DSL $(P=0.06)$, and a significantly higher concentration of 3 '-SL $(P=0.02)$ compared with $\mathrm{HC}$ calves. Yet, at $12 \mathrm{~h}$ of life no differences were detected in bCO within the distal jejunum or ileum among treatments; however, FC calves had a higher concentration of DSL $(P=0.04)$ in the colon when compared with $\mathrm{HC}$ calves. Species belonging to the genus Bifidobacteria have been shown to exhibit robust sialidase activity, as well as produce large amounts of acidic fermentation products (e.g., lactate and SCFA) when grown on 3'-SL and 6'-SL (Yu et al., 2013). A previous study that focused on the differences of Bifidobacteria in the small intestine of the same calves from the present study reported that calves fed HT colostrum displayed a higher prevalence of small intestinal Bifidobacterium at $6 \mathrm{~h}$ of life compared with calves fed fresh colostrum, whereas no differences were detected at $12 \mathrm{~h}$ among treatment groups in the prevalence of small intestinal Bifidobacterium (Malmuthuge et al., 2015). Therefore, we speculate that the low concentration of bCO in the intestine of $\mathrm{HC}$ fed calves at $6 \mathrm{~h}$ of life may be due to their utilization as a substrate for the growth of Bifidobacteria. Moreover, we speculate that no differences in the Bifidobacterium prevalence and the concentrations of $\mathrm{bCO}$ at $12 \mathrm{~h}$ of life indicates that the high concentration of bCO in FC calves at $6 \mathrm{~h}$ of life may have been metabolized by Bifidobacterium to achieve a similar prevalence this bacterial genus to that of $\mathrm{HC}$ calves at $12 \mathrm{~h}$ of life. To support our speculation, further correlation analysis was performed to explore the relationship between bCO and Bifidobacterium in the intestine of $\mathrm{FC}$ and $\mathrm{HC}$ calves. A negative correlation ( $\mathrm{r}$ $=-0.47, P=0.04$ ) between Bifidobacterium associated with the distal jejunum mucosa and bCO was observed, suggesting that the decreased concentrations of $\mathrm{bCO}$ may be due to their metabolism by Bifidobacterium in the small intestine of $\mathrm{HC}$ calves. However, additional bacterial genera in the intestine may also metabolize $\mathrm{bCO}$, such as Bacteroides, and certain species belonging to this genus have been shown to cleave and catabolize sialic acid (Marcobal et al., 2011). Future studies involving more in-depth analysis of the gut microbiota composition and population changes between $\mathrm{HC}$ and FC would help us determine the exact causative factor for the observed lower concentrations of $\mathrm{bCO}$ in the gut of $\mathrm{HC}$ calves. In addition, recent studies have reported biological effects of sialylated OS, including their ability to inhibit pathogenic E. coli K99 (Martin et al., 2002) and their capability to enhance the absorption of IgG (Gill et al., 1999). Therefore, the high content of sialylated OS [e.g., 3'-SL $(2,390.0 \mu \mathrm{g} / \mathrm{g})]$ observed in HT colostrum in the present study suggests it may have a potential beneficial effect as a prebiotic to enhance the population of beneficial microorganisms. Future studies are needed to understand the role of bCO in the intestine of neonatal calves and their interactions with the immune system and intestinal microbiota.

To our knowledge, the present study is the first to characterize the concentration of bCO from fresh and HT colostrum throughout the intestine of neonatal dairy calves, as well as to investigate the effect of heat treatment on the concentration of bCO in colostrum. In conclusion, the heat treatment of colostrum increased the concentration of free bCO in colostrum when compared with fresh colostrum. Heat treatment at $60^{\circ} \mathrm{C}$ for 60 min may release sialylated bCO from colostrum proteins and lipids, thus increasing the amount of free bCO. It was also determined that FC calves displayed a higher concentration of $\mathrm{bCO}$ at $6 \mathrm{~h}$ of life in the intestine compared with $\mathrm{HC}$ calves, which may sug- 
$6 \mathrm{~h}$ distal jejunum

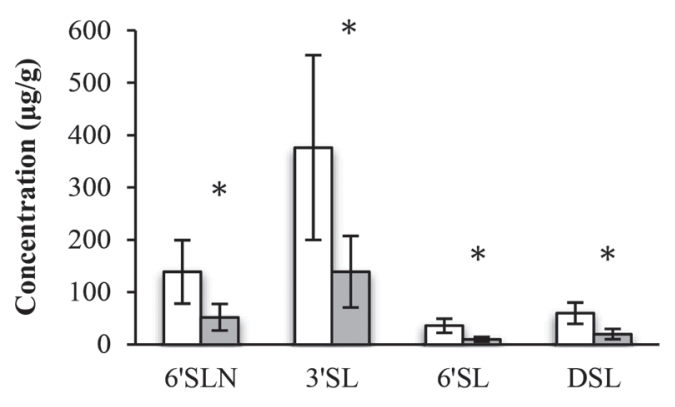

$6 \mathrm{~h}$ ileum

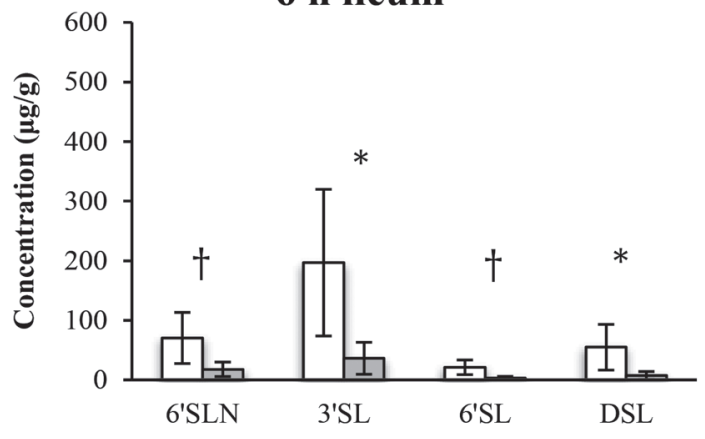

$6 \mathrm{~h}$ colon

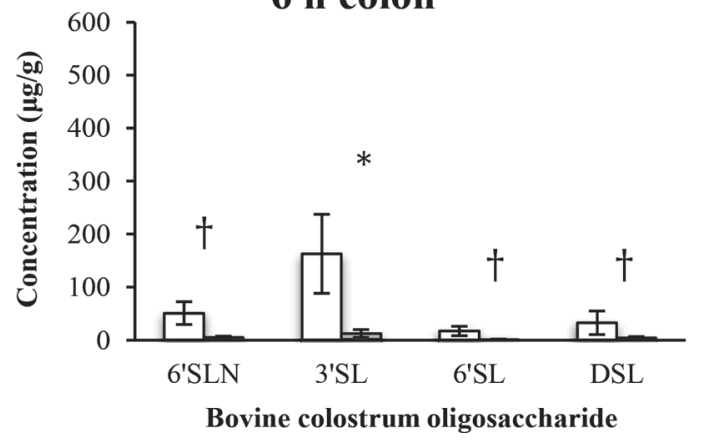

$12 \mathrm{~h}$ distal jejunum

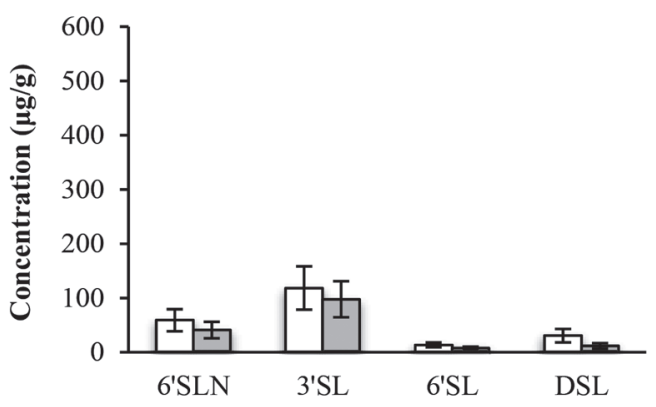

$12 \mathrm{~h}$ ileum

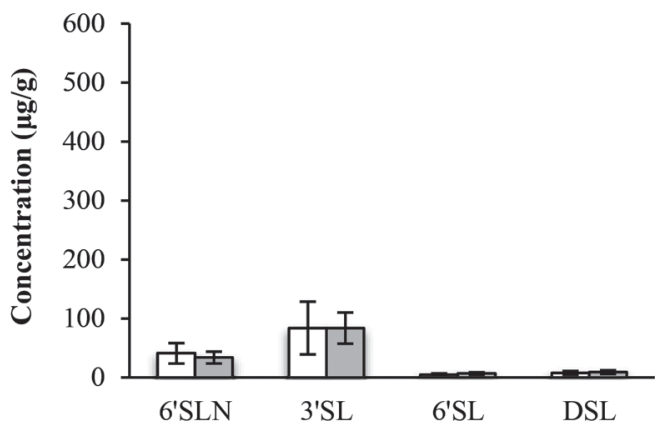

$12 \mathrm{~h}$ colon

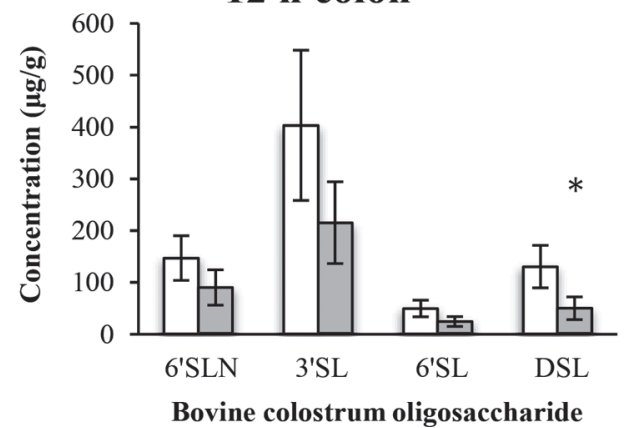

Figure 2. The concentration $(\mu \mathrm{g} / \mathrm{g})$ of bovine colostrum oligosaccharides in the intestine of calves fed fresh and heat-treated colostrum. Bars represent mean \pm SEM, with white bars representing calves fed fresh colostrum and gray bars representing calves fed heat-treated colostrum. $3^{\prime}$-SL $=3^{\prime}$-sialyllactose; $6{ }^{\prime}$-SL $=6$ '-sialyllactose; $6^{\prime}$-SLN $=6^{\prime}$-sialyllactosamine; DSL $=$ disialyllactose. ${ }^{*} P<0.05, \dagger 0.05<P<0.10$.

gest a variation in their metabolism due to the lower prevalence of Bifidobacterium. Our study suggests that heat treatment may have a potential prebiotic benefit in regard to providing more substrate to beneficial microorganisms in the gut of the neonatal calf, such as Bifidobacterium.

\section{ACKNOWLEDGMENTS}

We thank Alberta Livestock and Meat Agency Ltd. (Edmonton, Canada), Alberta Milk (Edmonton, Canada), Lallemand Inc. (Montreal, Canada), and the Natural Sciences and Engineering Research Council of Canada (NSERC) for funding. We also thank Lisa Nikolai and Yuan Yuan Zhao (University of Alberta) for their assistance with sample analysis.

\section{REFERENCES}

Brady, M. P., S. M. Godden, and D. M. Haines. 2015. Supplementing fresh bovine colostrum with gut-active carbohydrates reduces passive transfer of immunoglobulin G in Holstein dairy calves. J. Dairy Sci. 98:6415-6422.

CCAC. 1993. Guide to the care and use of experimental animals. 2nd ed. Vol. 1. Canadian Council on Animal Care, Ottawa, ON, Canada.

Engfer, M. B., B. Stahl, B. Finke, G. Sawatzki, and H. Daniel. 2000. Human milk oligosaccharides are resistant to enzymatic hydrolysis 
in the upper gastrointestinal tract. Am. J. Clin. Nutr. 71:15891596.

Firon, N., S. Ashkenazi, D. Mirelman, I. Ofek, and N. Sharon. 1987. Aromtaic alpha-glycosides of mannose are powerful inhibitors of the adherence of type 1 fimbriated Escherichia coli to yeast and intestinal epithelial cells. Infect. Immun. 55:472-476.

Fong, B., K. Ma, and P. McJarrow. 2011. Quantification of bovine milk oligosaccharides using liquid chromatography-selected reaction monitoring-mass spectrometry. J. Agric. Food Chem. 59:9788-9795.

Gill, R. K., S. Mahmood, and J. P. Nagpaul. 1999. Functional role of sialic acid in IgG binding to microvillus membranes in neonatal rat intestine. Biol. Neonate 76:55-64.

Jantscher-Krenn, E., C. Marx, and L. Bode. 2013. Human milk oligosaccharides are differentially metabolized in neonatal rats. Br. J. Nutr. 110:640-650.

Kent-Dennis, C. 2014. Effects of heat-treatment of colostrum on the development of calves in the neonatal and pre-weaned periods. MS Thesis. University of Alberta, Edmonton, Alberta, Canada.

Kobata, A. 1977. Milk glycoproteins and oligosaccharides. Page 423 in The Glycoconjugates. Vol. I. M. I. Horowitz and W. Pigman, ed. Academic Press, New York, NY.

Malmuthuge, N., Y. Chen, G. Liang, L. A. Goonewardene, and L. L. Guan. 2015. Heat-treated colostrum feeding promotes beneficial bacteria colonization in the small intestine of neonatal calves. J. Dairy Sci. 98:8044-8053.

Marcobal, A., M. Barboza, E. D. Sonnenburg, N. Pudlo, E. C. Martens, P. Desai, C. B. Lebrilla, B. C. Weimer, D. A. Mills, J. B. German, and J. L. Sonnenburg. 2011. Bacteroides in the infant gut consume milk oligosaccharides via mucus-utilization pathways. Cell Host Microbe 10:507-514.

Martin, M. J., S. Martin-Sosa, and P. Hueso. 2002. Binding of milk oligosaccharides by several enterotoxigenic Escherichia coli strains isolated from calves. Glycoconj. J. 19:5-11.

Martin-Sosa, S., M. J. Martin, L. A. Garcia-Pardo, and P. Hueso. 2003. Sialyloligosaccharides in human and bovine milk and in infant formulas: Variations with the progression of lactation. J. Dairy Sci. 86:52-59.
Meganck, V., G. Hoflack, and G. Opsomer. 2014. Advances in prevention and therapy of neonatal dairy calf diarrhea: A systematical review with emphasis on colostrum management and fluid therapy. Acta Vet. Scand. 56:75.

Nakamura, T., H. Kawase, K. Kimura, Y. Watanabe, and M. Ohtani. 2003. Concentrations of sialyloligosaccharides in bovine colostrum and milk during the prepartum and early lactation. J. Dairy Sci. $86: 1315-1320$.

National Animal Health Monitoring System. 2011. Dairy Heifer Raiser, 2011. USDA-Anim. Plant Health Insp. Serv. Vet. Serv., Ft. Collins, $\mathrm{CO}$

Neeser, J. R., M. Golliard, and S. D. Vedovo. 1991. Quantitative determination of complex carbohydrates in bovine milk and in milkbased infant formulas. J. Dairy Sci. 74:2860-2871.

Short, D. M., D. A. Moore, and W. M. Sischo. 2016. A randomized clinical trial evaluating the effects of oligosaccharides on transfer of passive immunity in neonatal dairy calves. J. Vet. Intern. Med. 30:1381-1389

Tao, N., E. J. DePeters, S. Freeman, J. B. German, R. Grimm, and C. B. Lebrilla. 2008. Bovine milk glycome. J. Dairy Sci. 91:3768-3778.

Vasseur, E., F. Borderas, R. I. Cue, D. Lefebvre, D. Pellerin, J. Rushen, K. M. Wade, and A. M. de Passille. 2010. A survey of dairy calf management practices in Canada that affect animal welfare. J. Dairy Sci. 93:1307-1315.

Villettaz Robichaud, M., S. M. Godden, D. M. Haines, D. B. Haley, D. L. Pearl, J. Rushen, and S. LeBlanc. 2014. Addition of gut active carbohydrates to colostrum replacer does not improve passive transfer of immunoglobulin G in Holstein dairy calves. J. Dairy Sci. 97:5700-5708.

Weaver, D. M., J. W. Tyler, D. C. VanMetrem, D. E. Hostetler, and G. M. Barrington. 2000. Passive transfer of colostral immunoglobulins in calves. J. Vet. Intern. Med. 14:569-577.

Yu, Z.-T., C. Chen, and D. S. Newburg. 2013. Utilization of major fucosylated and sialylated human milk oligosaccharides by isolated human gut microbes. Glycobiology 23:1281-1292. 